\title{
Under-five Mortality and Associated Factors among Children Born from 15-49 Years Old Mothers in Haramaya Town, Eastern Ethiopia
}

Mohammed Ahmed ( $\square$ mamexahmed@gmail.com )

Haramaya University

Melake Demena

Haramaya University

Zelalem Teklemariam

Haramaya University

\section{Research Article}

Keywords: Under-five mortality, Haramaya, Eastern Ethiopia

Posted Date: August 10th, 2021

DOI: https://doi.org/10.21203/rs.3.rs-799138/v1

License: (c) (i) This work is licensed under a Creative Commons Attribution 4.0 International License.

Read Full License 


\section{Abstract}

Background: The global under-five mortality rate has dropped from almost 90 deaths per 1,000 live births in 1990 to 43 in 2015. The Ethiopian Mini Demographic Health Survey, 2019 shows 55 under-five deaths per 1,000 live births. In the eastern part of Ethiopia, evidence from the Kersa Health and Demographic Surveillance System in Kersa district of East Hararghe Zone, Oromia Region suggested the decline of under-five mortality rate from 131.8 per 1000 live births in 2008 to 77.4 per 1000 live births in 2013 . The death rates still remain far from the Sustainable Development Goals' target reduction to 25 or less per 1000 live births by 2030 . However, the magnitude and determinants of under-five mortality is not studied in Haramaya town.

Objective: To assess the under-five mortality rate and associated factors among children born during August 07, 2015- August 06, 2020 in Haramaya town, east Ethiopia by August 07-31/2020.

Methodology: Quantitative cross-sectional population-based study was conducted on 391 pairs of 15-49 years old mothers and their live-born under-five children selected using systematic random sampling technique from Haramaya town to cmpare mortality between $<=24$ and $>=25$ mother's age groups. Data were collected using interview-based questionnaire; double entered into EpiData 3.1; and then exported to statistical package for social sciences program version 20.0 for analysis. Binary logistic regression analysis ( $p$-value $<0.20$ ) was performed to examine crude association of predictors with under-five mortality, and then multiple logistic regression analysis ( $p$-value $<0.05)$ to measure the statistical association.

Results: The death of 28 out of 372 live births gave an under-five mortality rate of 75 per 1000 live births. Children born in households with less than 6 members had 7. 98 times higher odds of dying than those born in households with at least 6 members ( $A O R=7.98,95 \% \mathrm{Cl}=1.59-40.17)$. Those children who did not feed colostrum were associated with 17.45 times increased risk of under-five deaths compared to colostrum-fed ones $(\mathrm{AOR}=17.45,95 \% \mathrm{Cl}=6.54-46.55)$.

Conclusion: The study suggests that 75 per 1000 live births die before celebrating their fifth birth day. Household size and colostrum feeding are the significantly associated factors.

Recommendation: All concerned should inform the mothers the role of identified factors like household size and colostrum feeding in child survival.

\section{Introduction}

\subsection{Back ground}

The child mortality rate (U5MR) has been widely used as an indicator of equality and human development (Alimohamadi et al., 2019). The U5MR is defined as the probability (per 1,000 live births) that a child will die before reaching the age of five if subject to current age-specific mortality rates 
(Rostami et al., 2015). It is an important indicator that reflects the health of children and the development of the economy and culture of a country or region (Cao et al., 2017). It is one of the health indicators used by the World Health Organization (WHO) to assess a country's progress with improving the health of its citizen (Mdala and Mash, 2015). The mortality of children under 5 years of age forms Goal 3 of the Sustainable Development Goals (SDG 3) to reduce the U5MR to at least as low as 25 per 1000 live births by 2030 (United Nations, 2018). In 1990, the United Nations Development Program (UNDP) introduced the Human Development Index (HDI) which has three aspects: longevity, knowledge, and life standards respectively measured by life expectancy at birth, a combination of adults' literacy and enrollment rate, and Gross Domestic Product (GDP) per capita with the main aim of creating a more comprehensive measure of human development program (Alimohamadi et al., 2019).

Globally there has been an overall decrease in under-five mortality since 1990 when many countries started working towards the fourth Millennium Development Goal (MDG), which aimed to decrease underfive mortality by two-thirds by the year 2015 (Mdala and Mash, 2015). The number of under-five deaths worldwide has declined from nearly 12.7 million in 1990 to 6.3 million in 2013. Consequently, the global U5MR has dropped from almost 90 deaths per 1,000 live births in 1990 to 46 in 2013 (Kipp et al., 2016). From 1990 to 2015, the global rate of U5MR declined by more than half and reached 43 per 1000 live births which was less than MDG 4 and far from the target Sustainable Development Goals (SDGs) to end preventable deaths of children under 5 years by 2030 (Alimohamadi et al., 2019). However, this progress is not equally distributed at national and sub-national levels (Rostami et al., 2015).

From an ecological study in West and South Asian countries, the highest rate of decrease was related to India (167.6 to 59.9 in 100 live births from 1980-2010) and Iran (109.9 to 19.2 in 100 live births from 1980-2010) (Alimohamadi et al., 2019). There are few studies on sub-national child mortality (CM) in Iran, but a published report by the Iranian Ministry of Health showed that in 2010 , more than $91 \%$ of mortality in the neonatal period and more than $63 \%$ of mortality 1 to 59 months after birth occurred in Iranian hospitals (Rostami et al., 2015). Deaths in neonates accounted for more than $50 \%$ of all deaths among under-5 children during the 24 consecutive years under investigation in Beijing (Cao et al., 2017).

African children are nearly 16 times more likely to die under age five than children from high-income nations, though progress in Africa is being made (Kipp et al., 2016). U5MR in the sub-Saharan region has remained unabated (Yaya et al., 2018). Many countries, especially those from sub-Saharan Africa, were unable to reach the Millennium Development Goal for under- 5 mortality reduction by 2015 (Mdala and Mash, 2015). The current U5MR (per 1,000 live births) was; 133 in the Republic of Chad, 104 in the Democratic Republic of Congo, 95 in Mali, 127 in Niger, and 69 in Zimbabwe (Yaya et al., 2018).

In Ethiopia, it declined substantially in most of the Health and Demographic Surveillance System (HDSS) sites during the last 10-15 years (Amare et al., 2016). For instance, evidence from the Kersa HDSS in Kersa district of East Hararghe Zone, Oromia Region, Eastern Ethiopia suggested the decline of U5MR from 131.8 per 1000 live births in 2008 to 77.4 per 1000 live births in 2013 (Nega et al., 2015). The prevalence rate of under-five mortality in Ethiopia was 67 per 1000 live births from Ethiopian 
Demographic Health Survey (EDHS) 2016 (Central Statistical Agency and ICF, 2016). This represents a $60 \%$ decrease in under-five mortality over the period of 16 years since 2000 when there were 166 deaths per 1000 live births (Shewayiref and Setegn, 2020).

It seems that improving maternal education level, increasing age at marriage, and the birth gap between two births has an important role in decreasing U5MR in India (Alimohamadi et al., 2019). For girls there are also major benefits for the next generation: half of the reduction in under- 5 mortality achieved in the last 30 years may be attributable to increased maternal education (Glynn et al., 2018).

\subsection{Statement of the problem}

In 2015, it was estimated that 5.9 million children aged under 5 years died (Alimohamadi et al., 2019). Evidence from Ethiopian Mini Demographic Health Survey (EMDHS), 2019 shows 55 under-five deaths per 1,000 live births (Ethiopian Public Health Institute and ICF, 2019).

The younger the mother is, the higher is the risk of complications both for her and the child, and childbearing before age 16 is of particular concern (Sandoy et al., 2016). However, evidence from Ethiopian Demographic and Health Survey, 2016 showed that about 40\% of women had given their first birth before age of 17 years old (Berhanu, 2019). The World Health Organization estimates that infant deaths are $50 \%$ higher amongst babies born to mothers aged below 20 years (Johnson et al., 2019). Infant mortality and morbidity, preterm birth, low birth weight, and asphyxia are also significantly higher among infants born to women under age 20 compared to older women (Luseno et al., 2016). A child born to a teen mother is twice as likely to die before the first birthday as compared with the child of a woman in her 20s (Kamal and Hassan, 2015). The majority of child (6.36\%) death occurred due to the mothers age at birth is less than 18 years in Ethiopia (Dereje et al., 2018). These high rates of mortality and morbidity may be, in part, due to immature physical structure, low utilization rates of maternal and child health services, and low education levels among adolescents (Luseno et al., 2016). A range of demographic and socioeconomic factors are known to account for enormous disparities in the uptake of maternal health care in low- and middle-income countries (Sekine and Carter, 2019).

Globally almost $40 \%$ of all under-five deaths are due to preventable or treatable infectious causes, particularly bacterial pneumonia and diarrhea diseases, as well as birth complications and malnutrition (Mdala and Mash, 2015). Several studies have shown that the Mother To Child Transmission (PMTCT) for HIV and malnutrition have an important influence on childhood mortality (Mdala and Mash, 2015). There is also high neonatal mortality in many poor countries due to premature birth, birth asphyxia, and sepsis whereas the deaths in older children after the perinatal period have remained high due to low coverage of pneumococcal vaccine, poor sanitation and water supply, and poor food security in low-income countries, as well as displacement of populations in countries with war or conflict (Mdala and Mash, 2015). The U5MR increased by 7.20\% from 2013 to 2015 in Beijing, China where birth asphyxia, congenital heart disease, preterm/low birth weight, and other congenital abnormalities comprised the top five causes of death (Cao et al., 2017). The associated risk factors of under-five 
mortality in rural settings of Ethiopia include differences in regions, educational attainment, born in twin, place of delivery, availability of occupation of parents, age of mothers at first birth, breastfeeding status, birth order, religious belief, use of a contraceptive method, child vaccination, and family size (Shewayiref and Setegn, 2020). In the study in Ethiopian Somali Regional State, family size, preceding birth interval, birth order, breastfeeding status, and source of drinking water were significant determinants of under-five mortality in the region (Solomon et al., 2017).

Generally, it was observed that U5MR and maternal mortality rate had a decreasing trend from 19802010 (Alimohamadi et al., 2019). One of the most important causes of this decrease was the improvement of HDI; thus, by increasing educational levels, income per capita, and life expectancy we might observe a substantial reduction in maternal and child mortality rates (Alimohamadi et al., 2019). In a French study, it was seen that U5MR decreased from 1990 to 2011 in all low- and middle-income countries and this decrease was influenced by factors such as improvement of health care and economic status (Alimohamadi et al., 2019). The reduction in mortality was consistent with changes in the proximate determinants of child survival in Bangladesh which included maternal factors, environmental contamination, nutrient deficiency, personal illness control, and injury (Chowdhury et al., 2017). Immunization and management of childhood illnesses are two important personal illness control measures, which have contributed enormously in reducing under-five mortality (Chowdhury et al., 2017). Health and population programs have been effective in increasing immunization coverage, use of ORS (Oral Rehydration Solution) for managing diarrheal diseases, and increasing contraceptive use (Chowdhury et al., 2017). India achieved an impressive decline in under-five mortality; from 167.5 in 1980 to 45.2 per 1000 live births in 2015 and reduced diarrhea mortality was an important contributing factor (Choudhary et al., 2019). ORS use and reduction in stunting were the two key interventions, each accounting for around $32 \%$ of the lives saved during this period in the country (Choudhary et al., 2019). Steadily increased contraceptive use during the last couple of decades from $40 \%$ in 1990 to $62 \%$ in 2014 has reduced the risk of $\mathrm{CM}$ associated with higher-order births, short birth intervals and large family size, which might have contributed to reducing overall CM (Chowdhury et al., 2017).

The under-five mortality rates, although reduced from 67 per 1000 live births evidence from EDHS, 2016 (Central Statistical Agency and ICF, 2016) to 55 per 1000 live births from EMDHS, 2019 (Ethiopian Public Health Institute and ICF, 2019), remain far from the SDGs target. The study analyzed data from the EDHS, 2016 was based on secondary data the major limitation was that some important determinant factors of under-five mortalities like previous death of a child and maternal TT immunization were missed due to high missing values in the data. The other weakness of the study was the mother's recall of events that took place for the past five years preceding the survey which was subject to recall bias (Berhanu, 2019).

Knowledge about the current under-five mortality and its determinant factors plays a great role in adapting different strategies and methods to achieve the desired goal, but there is little known about it. This knowledge is not only useful for enabling we to achieve SDGs desired target of reduction in underfive mortality, but with proper measures, it's possible to reduce the aftermath consequences for the country. Hence further investigation had to be conducted including variables not included in this study 
and to use spatial models to account spatial variation of experiencing under-five mortality since regional variations are significant (Berhanu, 2019). However, the magnitude and determinants of under-five mortality is not studied in Haramaya town.

Therefore, this study aimed to examine the under-five mortality rate and associated factors among those children born five years before the study in the town.

\subsection{Significance of the study}

Haramaya town health office and East Hararghe zonal health department may utilize the findings of this study to reduce mortality of under-five children. The results might have given clues for planning on the areas of relevant programs that were suggested by the study. The study also has put a basis for future studies.

\subsection{Objectives}

\subsubsection{General Objective}

- To assess the under-five mortality rate and its associated factors among children born during August 07, 2015- August 06, 2020 in Haramaya town by August 07-31/2020

\subsubsection{Specific Objectives}

- To determine the under-five mortality rate among the last children born in the past five years in Haramaya town

- To identify the factors associated with under-five mortality among the last children born in the past five years in Haramaya town

\section{Literature Review}

\subsection{Under-five Mortality Rate}

An analysis of the Bhutan National Health Survey 2012 showed that Bhutan's UFM rate was 37 per 1000 live births (Dendup et al., 2018). Evidence from the Nepal Demographic and Health Survey (2001-2016) indicated a U5MR of 87.7 per 1000 live births (Ghimire et al., 2019). In Ethiopia, it was approximately 67 per 1000 live births from 2016 Nationwide Survey Data analysis; 4.1, 52.3 and 3.2 deaths per 1000 live births were attributable to being born to mothers aged $<15,15-25$ and $>25$ years when first gave birth respectively (Chaltu et al., 2019).

\subsection{Factors Associated with Under-five Mortality}

\subsubsection{Socioeconomic Factors}




\subsubsection{Mother's education}

Maternal education, especially secular education, is the single most important factor for improved child survival (Chowdhury et al., 2017). In a study conducted in 2015, the mean years of schooling showed a significant correlation with the decrease of mortality rates meaning as education level increased, health literacy of women rose as well which led to better health, better care of their children, and more attention of women to the health of their family, and thus reducing the mortality and morbidity in West and South Asian countries (Alimohamadi et al., 2019). Children of mothers with no schooling had 1.88 times higher mortality than those whose mothers had six or more years of schooling in Bangladesh (Chowdhury et al., 2017). The U5MR was found to be significantly lower among children born to parents who attended at least a high school education in Bhutan (Dendup et al., 2018). The odds of UFM were significantly lower, $62 \%$ and $77 \%$, among children whose fathers had a high school and tertiary level of education respectively and $69 \%$ lower among whose household head had received high school education (Dendup et al., 2018).

For instance, in South Africa, falling behind in school was the strongest risk factor for giving birth within the following two years (Glynn et al., 2018). The study results in Nigeria showed that the risk of childhood mortality is $26.7 \%, 39.7$ and $45.9 \%$ lower among the mothers having primary, secondary and tertiary education respectively than those with no formal education (Yaya et al., 2017). One of the pathways by which mothers' education affects child survival is through improved child care (Yohannes et al., 2017). This is probably because those with little education before marriage may be unable or poorly equipped to take appropriate reproductive health decisions that are important in reducing pregnancy-related complications (Adedokun et al., 2017). Increased schooling has been associated with better health of women and their children in Zambia (Sandoy et al., 2016). An analysis of the 2011 EDHS data reveals that the risk of dying for a child born to an uneducated mother was 2.13 times higher compared to a child whose mother had primary and higher education. Also in a Gilgel Gibe field research of determinants of UFM, children born to mothers whose educational level was below elementary were 14 times more likely to die compared to children whose mothers' education is above elementary (Yohannes et al., 2017). Similarly, evidence from EDHS 2016 data analysis suggests that deaths among under-five children differed significantly with the level of mothers' education, with those of relatively higher education, having a lower chance of experiencing under-five deaths (P-value < 0.001) (Berhanu, 2019). Children born to a mother with no education at all were associated with a 2.61 times increased risk of under-five deaths compared to being born to a mother with higher education ( $\mathrm{OR}=2.610,95 \% \mathrm{Cl}: 1.598,4.265)$; children from mother with only primary education were 2.27 times more likely to at the risk of under-five mortality $(\mathrm{OR}=2.271,95 \% \mathrm{Cl}: 1.398,3.687)$, while children born to mother with secondary education were 2.163 times more likely to die before celebrating their fifth birthday (OR=2.163, 95\% Cl: $1.184,3.534)$ compared to being born to mother with higher education, keeping all other covariates constant (Berhanu, 2019). Evidence from Kersa HDSS in Kersa district of Eastern Hararghe, Oromia, Ethiopia also shows that maternal educational status was significantly associated with under-five children's mortality OR 1.31 $(1.13,1.49)$ (Melkamu et al., 2015). 


\subsubsection{Income}

Children from low asset category households had on average 1.17 times higher mortality rate than those from high asset category households in Bangladesh (Chowdhury et al., 2017). The odds of UFM reduced significantly with increasing wealth quintiles and were lower among those born to working mothers (Dendup et al., 2018). The risk of childhood mortality was significantly lower in the middle, richer and richest (11.1\%, 37.5 and $49 \%$ ) economic quintiles respectively when compared to the risk of childhood mortality with a female spouse who is poorest in Nigeria (Yaya et al., 2017). Low empowerment, indicated by low income and low decision-making power is significantly associated with the likelihood of experiencing pregnancy complications in the study area as those with low empowerment are (OR 3.962, $\mathrm{Cl} 0.937-1.083, \mathrm{P}<0.005)$ more likely to experience complications when compared with other categories (Adedokun et al., 2017). Evidence from Kersa HDSS in Kersa district of Eastern Hararghe, Oromia, Ethiopia also shows that low household wealth index was significantly associated with underfive children's mortality OR $1.26(1.10,1.43)$ (Melkamu et al., 2015).

\subsubsection{Household size}

Children born in households with at least 6 members experienced lower mortality rates. The likelihood of mortality was $66 \%$ lower $(95 \% \mathrm{Cl}: 0.21-0.55)$ among children born in households with > 5 members than those born in households with less than 6 members (Dendup et al., 2018). The possible influence of interaction between household size and other variables (wealth index, mother's working status, mother's education level, and place of residence) on UFM was found to be not significant, and is thus not reported. All variance inflation factors (VIFs) were $<10$, suggesting that multicollinearity was not a concern in the regression analysis (Dendup et al., 2018). A study in an Ethiopian Somali regional state suggested that family size was a significant determinant of under-five mortality in the region (Solomon et al., 2017). According to the EDHS 2011 data analysis, the mortality risk of children increases as the size of the family increases in the region. The risk of dying for a child born in family of size 4-6 is higher by 1.879 times relative to those born in family with size of 1-3 (reference category). Children born in a family with the size of seven and above have a significantly higher hazard rate than children born in a family with the size of 1-3, i.e., children born in a family of size seven and above have a 2.164 (HR=2.164, 95\% Cl: 1.987, 8.215) times higher risk of death as compared with children in the reference category (Solomon et al., 2017).

\subsubsection{Occupation of mother}

The employment status of mothers and husbands were identified as significantly associated factors with under-five deaths (P-value < 0.05). The odds of under-five mortalities were $18.4 \%(\mathrm{OR}=0.816,95 \% \mathrm{Cl}$. .666, .999) lower among women who were to working at all compared to those who were skilled or manual worker. The probability of child mortality, under-five, was $32 \%(\mathrm{OR}=0.679,95 \% \mathrm{Cl} . .533, .864)$ and less likely to occur among women with an unemployed husband and $22 \%(\mathrm{OR}=.783,95 \% \mathrm{Cl}$. .618, .991) less likely to occur among women whose husbands were professionally employed compared with those who were working as sales and others (Berhanu, 2019). 


\subsubsection{Availability of electricity}

The likelihood of UFM was also significantly higher among children born in households without electricity, in the eastern and central regions, and those living in rural areas (Dendup et al., 2018). The odds of UFM were significantly higher among children born in households without electricity (AOR $=1.81$, $p=0.026)$ and those born in the central $(A O R=1.72, p=0.025)$ and eastern $(A O R=2.09, p<0.001)$ regions (Dendup et al., 2018).

\subsubsection{Health-related Factors}

\subsubsection{Maternal TT immunization}

Multivariable analyses revealed the most common factor associated with mortality across all age subgroups was nonuse of tetanus toxoids (TT) vaccinations during pregnancy (aHR 2.28, 95\% $\mathrm{Cl} 1.68$, 3.09 for neonatal; aHR 1.86, 95\% Cl 1.24, 2.79 for post-neonatal; aHR 2.44, 95\% $\mathrm{Cl} 1.89,3.15$ for the infant; aHR 2.93, 95\% Cl 1.51, 5.69 for the child; and aHR 2.39, 95\% $\mathrm{Cl} 1.89,3.01$ for under-five mortality) (Ghimire et al., 2019).

\subsubsection{Contraceptive use}

Multivariable analyses revealed nonuse of contraceptives among mothers was the most common factor associated with mortality across all age subgroups (aHR 1.69, 95\% Cl 1.21, 2.37 for neonatal; aHR 2.69, $95 \% \mathrm{Cl} 1.67,4.32$ for post-neonatal; aHR 2.01, 95\% Cl 1.53, 2.64 for the infant; aHR 2.47, 95\% Cl 1.30, 4.71 for the child; and aHR 2.03, 95\% Cl 1.57, 2.62 for under-five mortality) (Ghimire et al., 2019).

\subsubsection{Place of delivery}

Nigeria observed that high stillbirth and early neonatal mortality rate have been long associated with unattended deliveries compared with hospital-based deliveries (Adedokun et al., 2017). Evidence from Ethiopian Demographic and Health Survey, 2016 showed that the percentage of under-five mortalities is higher among home deliveries, which is about $27.6 \%$ compared to $24.7 \%$ among health facility deliveries (Berhanu, 2019). Evidence from Kersa HDSS in Kersa district of Eastern Hararghe, Oromia, Ethiopia also suggested that place of delivery was significantly associated with under-five children's mortality OR $1.26(1.10,1.43) 1.016(1.013,1.12)$ (Melkamu et al., 2015).

\subsubsection{Colostrum feeding}

Colostrum feeding practice after birth was associated with UFM, whereas the rest of the health-related variables were not found to be significant (COR $=2.26, p=0.042$ ) (Dendup et al., 2018). According to a study conducted in Afambo district of Afar Regional State, the chi-square test showed that colostrum feeding was significantly associated $(p=0.035, p=0.006$ and $p=0.001)$ with the three indicators of child under-nutrition (stunting, wasting and underweight) respectively (Misgan et al., 2016).

\subsubsection{Bio-demographic Factors}




\subsubsection{Mother's age}

Mother's age was the key factor associated with UFM in Bhutan (Dendup et al., 2018). Multivariate analysis showed that having $>1$ under- 5 child death was associated with maternal age at delivery ( $<18$ or $>35$ ) of mothers in a study conducted in Iran (Anafcheh et al., 2018). Compared to those born to younger ( $\leq 25$ years) mothers, children born to mothers aged $36-40$ years, $41-45$ years, and more than 45 years had significantly lower odds of UFM (Dendup et al., 2018). Children born from mothers whose age less than or equal to 24 have a significantly lower risk of under-five mortalities (OR=0.295, 95\% Cl: .227,.383) compared to those born from mothers whose age is between 45 and 49 in Ethiopia (Berhanu, 2019).

\subsubsection{Mother's age at first marriage}

The U5MR was found to be higher among children whose mothers were older than 45 years, who were younger than 16 years when they first married (Dendup et al., 2018).

\subsubsection{Mother's age at first birth}

Maternal age at first birth was identified as a strong predictor of under-five mortalities in both bivariate and multivariate analysis after controlling for the effects of other covariates (Berhanu, 2019). A systematic review revealed that a mother's age at first birth is negatively correlated with infant mortality (IM) in Ethiopia. Its effect (except children born to mothers older than 20 years of age at first births) has a significant impact on CM (Yohannes et al., 2017). Similarly, the age of the mother at first birth was significantly associated with under-five mortalities in Ethiopia (P-value < 0.0001). The risk of under-five mortality was about $55.6 \%$ higher for births to mother give birth at earlier age 11 to 17 years compared with births to mothers 25 and higher years old (OR=1.556, 95\% Cl: 1.243, 1.949) (Berhanu, 2019).

\subsubsection{Sex of the child}

In Bangladesh, the present analysis examined under-five mortality in which the neonatal deaths formed the major part due to rapid decline in childhood mortality during age 1-4 years of life and the higher under-five mortality for male than female was due to lower female mortality during the neonatal period (Chowdhury et al., 2017). The under-five mortality rate steadily declined over the years from 128/1000 in 1994 to 48 in 2014 and females had 8\% lower mortality rates than males (Chowdhury et al., 2017). The U5MR was found to be higher among male children in Bhutan. Boys were 1.38 times more likely to die than girls $(p=0.055)$ (Dendup et al., 2018). The odds of under-five death were also higher for male children $(A O R=1.30, C l=[1.07,1.57], P<0.008)$ compared to females in Ethiopia (Chaltu et al., 2019).

\subsubsection{Number of births}

Several children is also another significant factor identified in the analysis, it was revealed that everexperienced complications may likely increase with the number of children, an interesting finding in this study, particularly with low contraceptive use (Adedokun et al., 2017). Children born to mothers who gave birth to more than 2 children had significantly higher odds of dying. The odds of death among children 
born to mothers who gave birth to 3-4 or more than 4 children were significantly higher than those born to mothers with less than 3 children (Dendup et al., 2018). The U5MR was found to be higher among children whose mothers had more than 4 births in Bhutan (Dendup et al., 2018).

\subsubsection{Previous death of a child}

Multivariable analyses revealed one of the most common factors associated with mortality across all age subgroups was mothers who reported previous death of a child [adjusted hazard ratio (aHR) 17.33, 95\% confidence interval (CI) 11.44, 26.26 for neonatal; aHR 13.05, 95\% Cl 7.19, 23.67 for post-neonatal; aHR $15.90,95 \% \mathrm{Cl} 11.38,22.22$ for the infant; aHR $16.98,95 \% \mathrm{Cl} 6.19,46.58$ for the child; and aHR 15.97, $95 \%$ Cl 11.64, 21.92 for under-five mortality (Ghimire et al., 2019).

\subsubsection{Birth order}

An increase in children's birth orders showed a tremendous negative impact on IM in both 2000 and 2005 EDHSs; particularly the 2nd and 3rd birth order were dominant determinants. The estimated hazard ratios of mortality were higher for first birth orders compared to second and third ones (Yohannes et al., 2017). The study result in Ethiopia indicates hazard ratio of children who had birth order fifth and above was 1.683 [95\% Cl: 1.190, 2.380]. This means children born at the fifth and above were 1.683 times more likely to die than children born at 1st-2nd order (Dereje et al., 2018). A study in an Ethiopian Somali regional state also suggested that birth order was a significant determinant of under-five mortality in the region (Solomon et al., 2017). According to this study, higher birth orders (>4) have the highest mortality risk. Children with these characteristics are 2.067 times more likely to die in age less than 5 relative to the reference group births of order one ( $\mathrm{HR}=2.067,95 \% \mathrm{Cl}$ : 1.098 to 8.256$)$. Children of order two through four are dying at a rate $23.6 \%$ higher than a child of order one ( $\mathrm{HR}=1.236,95 \% \mathrm{Cl}: 1.031$ to 12.199$)$. The confidence intervals for higher birth order and birth order two through four indicate that the rate could actually be as high as 8.256 and 12.199 and as low as 1.098 and 1.031, respectively (Solomon et al., 2017).

\subsubsection{Environmental Factors}

\subsubsection{Safe drinking water}

A study in an Ethiopian Somali regional state suggested that the source of drinking water was a significant determinant of under-five mortality in the region (Solomon et al., 2017). The risk of dying for a child born in a family without access to pipe drinking water is higher by $76 \%$ relative to those born in a family with access to pipe drinking water. The $95 \%$ confidence interval $(1.421,9.373)$ implies that the risk of death of children whose source of water is not pipe water is 1.421 as low and 9.373 as high as those in the reference group (Solomon et al., 2017).

\subsubsection{Safe sanitation facilities}


The likelihood of UFM was 1.49 times higher for those children born in households without safe sanitation facilities than their counterparts $(p=0.012)$ (Dendup et al., 2018).

\subsubsection{Solid fuel use}

Furthermore, the U5MR was significantly higher among children born in households that used solid fuel. The likelihood of UFM was 2.18 and 1.95 times significantly higher among children born in households without safe sanitation and those that used solid fuel for cooking respectively (Dendup et al., 2018).

\subsection{Conceptual Framework}

See Figure 1

\section{Methodology}

\subsection{Study Area and Period}

Haramaya town is situated in East Hararghe Zone, Oromia Regional State, Ethiopia. It is located $21 \mathrm{~km}$ Northwest of Harar town and $505 \mathrm{~km}$ East of Addis-Ababa, the capital city of Ethiopia. The elevation in the site ranges from 2018 meters to 2422 meters above sea level (m. a. s. I). The watershed lies at a UTM (Universal Transverse Mercator) coordinate of 171212 East and 1040190 North. It is characterized by a "Woina-Dega" agro-climatic zone that receives a mean annual rainfall of $775.9 \mathrm{~mm}$. The monthly rainfall in the site is more than $100 \mathrm{~mm}$ from April to September, except June $48.4 \mathrm{~mm}$. The wettest month is August, $151.9 \mathrm{~mm}$. The daily temperature in the site ranges from $10^{\circ} \mathrm{C}-25^{\circ} \mathrm{C}$. The livelihood in the area is based on agriculture. Therefore, different agricultural practices are practiced within the Lake Haramaya watershed (Haile and Ararso, 2016). The town has one primary hospital and is divided into 3 administrative kebeles and 24 sub-kebeles where 9, 7 and 8 of them belong to kebeles 01,02 and 03 respectively. The estimated population of the town was 50960 of which 8373 were expected to be children under-five years of age. Of the population, 19030 (3127 under-five), 18214 (2993 under-five) and 13716 (2253 under-five) were expected to live in kebeles 01,02 and 03 respectively. The childhood mortality status in the town is yet unknown. The study was conducted starting from August 07-31/2020.

\subsection{Study Design}

A community-based cross-sectional study design was selected.

\subsection{Source and Study Population}

\subsubsection{Source Population}


All pairs of 15-49 years old mothers lived and their children born alive in Haramaya town in the past five years.

\subsubsection{Study Population}

All 15-49 years old mother-live-born under-five child pairs who were living in randomly selected subkebeles of Haramaya town during the study.

\subsection{Inclusion and exclusion criteria}

\subsubsection{Inclusion criteria}

All 15-49 years old mothers who had had live births in the past five years were included.

\subsubsection{Exclusion criteria}

Mothers who either had had multiple births like a twin or couldn't respond due to serious illness were excluded. Multiple births were excluded because of the known higher risk of neonatal mortality due to pregnancy complications and preterm birth amongst multiple births compared to singleton births to avoid potential confounding effects (Dendup et al., 2018, Ghimire et al., 2019).

\subsection{Sample size determination}

The sample size calculated using the single population proportion formula; $n=\left(z_{a / 2}\right)^{2} \pi(1-\pi) / d^{2}$ for specific objective one (to determine the under-five mortality rate among the last children born in the past five years in Haramaya town) is as follows where $n$ is the sample size, $\pi$ is population proportion and $d$ is precision required in \%

$=(1.96)^{2 \star 0.067(1-0.067) / 0.05^{2}}$

$=3.8416 * 0.067(0.933) / 0.0025$

$=0.24 / 0.0025$

$=96$

Furthermore, the sample size was also calculated with the double population proportion formula;

$$
\mathrm{N}=2 *\left[\left(\mathrm{z}_{\mathrm{cv}} \sqrt{2 \bar{p}(1-\bar{p})}+\text { Zpower } \sqrt{\mathrm{p} 1(1-\mathrm{p} 1)+\mathrm{p} 2(1-\mathrm{p} 2)}\right)^{2}\right]:
$$

$$
\left(\mathrm{p}_{1}-\mathrm{p}_{2}\right)^{2}
$$


for specific objective two of this study which was to identify the factors associated with under-five mortality among the last children born in the past five years in Haramaya town as indicated in table1 below using the following assumptions; confidence level of $95 \%$ and $5 \%$ significance level (Berhanu, 2019).

$\mathrm{r}=\mathrm{n} 1 / \mathrm{n} 2=1: 2$

$Z a / 2=1.96$ (the value of the standard normal distribution curve corresponding to confidence interval $95 \%)$

$Z \beta=0.84$ (the value of the standard normal distribution curve corresponding to $80 \%$ power

de $=1.5($ design effect)

$\mathrm{P} 1=$ percent outcome among unexposed

$\mathrm{P} 2=$ percent outcome in exposed

$\mathrm{P}=\underline{\mathrm{P} 1+\mathrm{P} 2}$

2

Table 1. Sample size calculation

\begin{tabular}{|lccccccc|}
\hline Variable & $\begin{array}{l}\text { P1 } \\
(\%)\end{array}$ & $\begin{array}{l}\text { P2 } \\
(\%)\end{array}$ & P (\%) & Cl & Power & $\begin{array}{l}\text { Unexposed to the } \\
\text { exposed ratio }\end{array}$ & $\begin{array}{l}\text { Total } \\
\text { sample size }\end{array}$ \\
\hline $\begin{array}{l}\text { Maternal } \\
\text { education }\end{array}$ & 4.7 & 34.9 & 19.8 & $95 \%$ & $80 \%$ & 0.077 & 52 \\
\hline $\begin{array}{l}\text { Maternal age } \\
\begin{array}{l}\text { Age at first } \\
\text { birth }\end{array}\end{array}$ & 10.5 & 50 & 30.25 & $95 \%$ & $80 \%$ & 2.054 & 40 \\
\hline \begin{tabular}{l} 
Birth order \\
\hline
\end{tabular} & 4.8 & 49 & 26.9 & $95 \%$ & $80 \%$ & 0.504 & 237 \\
\hline
\end{tabular}

Since the sample size calculated for specific objective two accommodated the largest sample size, it was $(237 \times 1.5)+10 \%=391$. Therefore, the minimum total sample size considered to undertake the study was 391 after considering design effect of 1.5 and non response rate of $10 \%$.

\subsection{Sampling procedure/technique}

Participants were selected using a two-stage sampling among 638 mothers of 15-49 years old age identified before the study whose births had been registered by the vital events registration agency. A 
simple random sampling method was used to select sub-kebeles from all the 3 kebeles of Haramaya town proportional to their population size. Accordingly, 3 of the 9 sub-kebeles of kebele 01 (sub-kebeles 1, 4 and 7); 2 of the 7 of 02 ( 3 and 6 ) and 2 of the 8 of 03 ( 2 and 7) were selected. Then systematic random sampling to select participants independently from the selected sub-kebeles proportional to their respective number of mothers of under-five children identified. Since the sampling interval was 1 for all sub-kebeles, the sample was taken starting from the first cases. Finally, the study was conducted on 391 participants as shown in figure 3 below.

\subsection{Data collection methods}

\subsubsection{Data Collection Tool}

The data collection tool consisted of socioeconomic, socio-demographic, environmental and healthrelated characteristics that would affect under-five mortality. Questionnaire for primary data which included 17 structured and open-ended questions was adopted from different literatures put in its review as socioeconomic, bio-demographic, environmental and health-related factors (Dendup et al., 2018, Ghimire et al., 2019, (Biniyam et al., 2018, Berhanu, 2019, Chaltu et al., 2019, Solomon et al., 2017) in English language first and then translated in to Afan Oromo by language experts and again the Afan Oromo version translated back to English to make it consistent. Data were collected using the Afan Oromo structured and open-ended questions.

\subsubsection{Data Collectors}

Three nurses who had previous experience in data collection were selected among my co-workers and given training. Then they collected data according to the schedule already set.

\subsubsection{Data Collection procedures}

Data were collected home-to-home using interview-based questionnaire from fifteen study participants daily for the first twenty two days, and then from fourteen participants daily for the last three days based on time availed for data collection. The data collection process was supervised and continuously followed up by the principal investigator throughout the data collection period.

\subsection{Variables}

\subsubsection{Dependent variable}

- Under-five mortality

\subsubsection{Independent variables}

- Mother's age 
- Mother's education

- Household size

- Mother's age at first marriage

- Income

- Number of births

- Birth order

- Occupation of mother

- Sex of the child

- Previous death of a child

- Safe drinking water

- Safe sanitation facilities

- Solid fuel use

- Maternal TT immunization

- Contraceptive use

- Place of delivery

- Colostrum feeding

\subsection{Operational definitions}

Under-five mortality: Mortality of the last child born in the past five years (yes, no)

Previous death of a child: Under-five death of any child other than the last one (yes, no)

Income: Economic/wealth status of the household in ETB (Ethiopian Birr) per month; ( $<1700$ ETB, >=1700 ETB) (Biniyam et al., 2018)

Safe drinking water: Household has access to a protected drinking water source (yes, no); piped tap, protected well and protected spring are safe water sources whereas surface water like a river, pond, etc. are unsafe

Safe sanitation facilities: Household has access to improved sanitation facilities (yes, no); water-flush toilet, ventilated improved pit latrine and traditional pit latrine are safe sanitation facilities whereas communal latrine, field or anywhere are unsafe

Use of solid fuel: Use charcoal, wood or kerosene for cooking (yes, no)

Maternal TT immunization: Tetanus toxoid injection status of mothers (one or no TT, two or more TT) Contraceptive use: Use of contraceptives in the mothers' experience (ever used, never used) 
Place of delivery: Place of delivery for the last birth under five years (health facility, home)

Colostrum feeding: Feeding colostrum soon after birth to the last child under five years (yes, no); colostrum is secreted with its potential benefits within 1 hour of birth (Gebretsadkan et al., 2020)

\subsection{Data quality control}

To maintain the quality of the data, data collectors were trained in data collection procedures. The questionnaire was carefully designed and prepared in English language first and then translated in to Afan Oromo by language experts and again the Afan Oromo version was translated back to English to make it consistent. Finally, the Afan Oromo version was used to collect data. Before actual data collection time, the questionnaire (tool) was pretested for validity and reliability in $10 \%$ of the sample in Aweday town. Data quality was also controlled by daily cleaning of data.

\subsection{Methods of data analysis}

Data were double entered into EpiData version 3.1; and then, cleared, coded, processed and analyzed using computer, statistical package for social sciences (SPSS) version 20.0. To descriptive statistics; frequencies and percentages were used. The U5MR was calculated as 'deaths per 1000 live births'. Multicollinearity checked among the independent variables was not there. Binary logistic regression analysis (Odds ratio, $80 \% \mathrm{Cl}$ and $\mathrm{P}$-value 0.20 ) was performed to examine the crude association of predictors with under-five mortality, and then multiple logistic regressions (Odds ratio, 95\% $\mathrm{Cl}$ and P-value 0.05 ) to measure the statistical association. In the multivariate analysis, backward logistic regression method was used with the Hosmer and Lomeshow googness-of-fit test, and the value of 0.431 was insignificant which means the final model was correct. Finally, the results were presented in texts, tables, and figures.

\subsection{Ethical considerations}

The study was conducted after the proposal was approved by HU, CHMS IHRERC (Haramaya University, College of Health and Medical Sciences Institutional Health Research Ethics Review Committee). Informed, voluntary, written and signed consent was taken from each mother or husband in case of a minor. Conflict of interest was controlled. Privacy and confidentiality of participants were assured. The selection of the mothers was also equitable and fair. There was no risk of participating in this study than taking few minutes from their time. The findings from this research revealed important information for the local health planners even though there was no direct payment for participating in the study. They also had the right to participate or not and even could withdraw at any time once decided to participate.

\section{Results}




\subsection{Socio demographic characteristics}

Out of the calculated sample of 391 mothers who had had singleton live births from August 07, 2015 to August 06, 2020 included in this study, 372 (95.14\%) responded to the home-to-home interview. The median of current mothers' age was 24.5 with a standard deviation of $+/-5.81824$. The range of mothers' age was 15 to 45 . The majority of the births (52.4\%) were males; $64.2 \%$ in households with not more than 5 members. Of the mothers, $86.0 \%$ fed their child colostrum (Table 2 ).

\section{2. Under-five Mortality Rate}

Out of 372 singleton live births from $7^{\text {th }}$ August 2015 to $6^{\text {th }}$ August 2020, 28 (7.5\%) died. This gave a weighted U5MR of 75 per 1000 live births. Children born in households with less than 6 members experienced higher mortality rates. Significantly higher U5MR was also recorded among children who did not feed colostrum $(p<0.001)$.

Table 2. Socio-demographic characteristics and distribution of under-five mortality rate in Haramaya town, east Ethiopia, 2016-2020 ( $n=372)$ 


\begin{tabular}{|c|c|c|c|c|}
\hline \multirow{2}{*}{ Variables } & \multirow[t]{2}{*}{$\mathrm{N}(\%)$} & \multicolumn{2}{|c|}{ Under-five mortality } & \multirow[t]{2}{*}{$\mathrm{U}_{5} \mathrm{MR}^{\mathrm{a}}\left(95 \% \mathrm{CI}^{\mathrm{b}}\right)$} \\
\hline & & Yes (\%) & No $(\%)$ & \\
\hline Mother's education & & & & \\
\hline No formal education & $120(32.3)$ & $9(7.5)$ & $111(92.5)$ & $75(27.0,123.0)$ \\
\hline Primary school & $150(40.3)$ & $13(8.7)$ & $137(91.3)$ & $87(41.0,132.0)$ \\
\hline $\begin{array}{l}\text { Secondary school \& } \\
\text { above }\end{array}$ & $102(27.4)$ & $6(5.9)$ & $96(94.1)$ & $59(12.0,105.0)$ \\
\hline Income (ETB) & $34(9.1)$ & $7(20.6)$ & $27(79.4))$ & $206(63.0,349.0)$ \\
\hline $\begin{array}{l}<1700 \\
>=1700\end{array}$ & $338(90.9)$ & $21(6.2)$ & $317(93.8)$ & $62(36.0,88.0)$ \\
\hline Household size & $239(64.2)$ & $22(9.2)$ & $217(90.8)$ & $92(55.0,129.0)$ \\
\hline $\begin{array}{l}<=5 \\
>5\end{array}$ & & $6(4.5)$ & $127(95.5)$ & $45(9.0,81.0)$ \\
\hline Occupation of mother & & $13(5.6)$ & 219 & $56(26.0,86.0)$ \\
\hline House wife & $232(62.4)$ & $5(12.5)$ & (94.4) & $125(18.0,232.0)$ \\
\hline Government employee & $40(10.8)$ & $5(19.2)$ & $35(87.5)$ & $192(30.0,355.0)$ \\
\hline Daily laborer & $26(7.0)$ & $5(6.8)$ & $21(80.8)$ & $68(9.0,126.0)$ \\
\hline Others & $74(8.6)$ & & $69(93.2)$ & \\
\hline Maternal TT immunization & & $5(11.6)$ & & $116(16.0,216.0)$ \\
\hline One or no TT & $43(11.6)$ & $23(7.0)$ & $38(88.4)$ & $70(42.0,98.0)$ \\
\hline Two or more TT & $329(88.4)$ & & $306(93.0)$ & \\
\hline Contraceptive use & & $16(9.8)$ & & $98(52.0,143.0)$ \\
\hline Never used & $164(44.1)$ & $12(5.8)$ & $148(90.2)$ & $58(26.0,90.0)$ \\
\hline Ever used & $208(55.9)$ & & $196(94.2)$ & \\
\hline Place of delivery & & $6(9.0)$ & & $90(19.0,160.0)$ \\
\hline Home & $67(18.0)$ & $22(7.2)$ & $61(91.0)$ & $72(43,101)$ \\
\hline Health facility & $305(82.0)$ & & $283(92.8)$ & \\
\hline Colostrum feeding & & $11(3.4)$ & & $34(14.0,54.0)$ \\
\hline Yes & $320(86.0)$ & & 309 (96.6) & 327 (195.0, \\
\hline No & $52(14.0)$ & (32.7) & $35(67.3)$ & 459.0) \\
\hline Mother's age & & & & \\
\hline$<=24$ & $187(50.3)$ & $12(6.4)$ & $175(93.6)$ & $64(29.0,100.0)$ \\
\hline$>=25$ & $185(49.7)$ & $16(8.6)$ & $169(91.4)$ & $86(46.0,127.0)$ \\
\hline Mother's age at first marriage & & & & \\
\hline $\begin{array}{l}<18 \\
>=18\end{array}$ & $372(100.0)$ & $28(7.5)$ & $344(92.5)$ & $75(48.0,102.0)$ \\
\hline Sex of the child & & & & \\
\hline Male & $195(52.4)$ & $16(8.2)$ & $179(91.8)$ & $82(43.0,121.0)$ \\
\hline Female & $177(47.6)$ & $12(6.8)$ & $165(93.2)$ & $68(30.0,105.0)$ \\
\hline Number of births & & & & \\
\hline$>4$ & $87(23.4)$ & $8(9.2)$ & $79(90.8)$ & $92(30.0,154.0)$ \\
\hline $3-4$ & $119(32.0)$ & $7(5.9)$ & $112(94.1)$ & $59(16.0,102.0)$ \\
\hline$<=2$ & $166(44.6)$ & $13(7.8)$ & $153(92.2)$ & $78(37.0,120.0)$ \\
\hline Previous death of a child & & & & \\
\hline Yes & 59 (15.9) & $6(10.2)$ & $53(89.8)$ & $102(22.0,181.0)$ \\
\hline No & $313(84.1)$ & $22(7.0)$ & $291(93.0)$ & $70(42.0,99.0)$ \\
\hline Birth order & & & & \\
\hline$>=$ Fourth & $133(35.8)$ & $10(7.5)$ & $123(92.5)$ & $75(30.0,121.0)$ \\
\hline Second or third & $156(41.9)$ & $10(6.4)$ & $146(93.6)$ & $64(25.0,103.0)$ \\
\hline First & $83(22.3)$ & $8(9.6)$ & $75(90.4)$ & $96(32.0,161.0)$ \\
\hline Safe drinking water & & & & \\
\hline Yes & $372(100.0)$ & $28(7.5)$ & $344(92.5)$ & $75(48.0,102.0)$ \\
\hline No & & & & \\
\hline
\end{tabular}




\begin{tabular}{|l|r|r|r|r|} 
Safe sanitation facilities & $95(25.5)$ & $8(8.4)$ & $87(91.6)$ & $84(27.0,141.0)$ \\
Yes & $277(74.5)$ & $20(7.2)$ & $257(92.8)$ & $72(42.0,103.0)$ \\
No & & & & \\
Solid fuel use & $356(95.7)$ & $26(7.3)$ & $330(92.7)$ & $73(46.0,100.0)$ \\
Yes & $16(4.3)$ & $2(12.5)$ & $14(87.5)$ & $125(-57.0,307.0)$ \\
No &
\end{tabular}

a Weighted under-five mortality rates as 'deaths per 1000 live births'; b Confidence interval; TT = tetanus toxoid

\subsection{Factors Associated with Under-five Mortality}

In bivariate analysis $(p<0.20)$, households earn less than 1700 ETB per month, households with less than 6 family members, mothers working as house wives, mothers aged $<=24$ years old, mothers who had more than 4 births, mothers who had never used any contraceptive, and children not colostrum fed were found to be candidates for multivariate analysis (Table 3).

Table 3. Crude association of predictors with under-five mortality of children in Haramaya town, east Ethiopia, 2016-2020 ( $n=372$ and $p<0.20)$ 


\begin{tabular}{|c|c|c|c|c|c|}
\hline \multirow[t]{2}{*}{ Iriables } & \multirow[t]{2}{*}{$\mathrm{N}(\%)$} & \multicolumn{2}{|c|}{$\begin{array}{l}\text { Under-five } \\
\text { mortality }\end{array}$} & \multirow[t]{2}{*}{ COR $(80 \% \mathrm{CI})$} & \multirow[t]{2}{*}{$\begin{array}{c}\mathrm{P}- \\
\text { value }\end{array}$} \\
\hline & & $\begin{array}{l}\text { Yes } \\
(\%)\end{array}$ & $\begin{array}{l}\text { No } \\
(\%)\end{array}$ & & \\
\hline \multicolumn{6}{|l|}{ ther's education } \\
\hline Secondary school \& & $102(27.4)$ & 6 & & 1.00 & \\
\hline above No formal & $120(32.3)$ & (5.9) & (94.1) & $0.77(0.28,2.11)$ & 0.735 \\
\hline education & $150(40.3)$ & & 111 & $1.04(0.44,2.46)$ & 0.958 \\
\hline Primary school & & (7.5) & (92.5) & & \\
\hline some (ETB) & $338(90.9)$ & 13 & 137 & 1.00 & \\
\hline$>=1700$ & $34(9.1)$ & (8.7) & (91.3) & $2.77(1.18,6.50)$ & 0.127 \\
\hline \multicolumn{6}{|l|}{$<1700$} \\
\hline usehold size & $133(35.8)$ & 21 & 317 & 1.00 & \\
\hline$>5$ & $239(64.2)$ & $(6.2)$ & (93.8) & $10.56(3.52,31.72)$ & 0.006 \\
\hline $\begin{array}{l}\quad<=5 \\
\text { cupation of mother }\end{array}$ & & 7 & 27 & & \\
\hline \multicolumn{2}{|l|}{ cupation of mother } & $(20.6)$ & $(79.4))$ & $\begin{array}{r}1.00 \\
0.23(0.08,0.62)\end{array}$ & 0.060 \\
\hline House wife & $232(62.4)$ & 6 & 127 & $0.54(0.17,1.70)$ & 0.493 \\
\hline Government employee & $40(10.8)$ & $(4.5)$ & (95.5) & $0.53(0.15,1.86)$ & 0.518 \\
\hline Others & $74(8.6)$ & 22 & 217 & & \\
\hline \multicolumn{2}{|l|}{ iternal TT immunization } & $(9.2)$ & $(90.8)$ & 1.00 & \\
\hline Two or more TT & $329(88.4)$ & & & $2.29(0.89,5.92)$ & 0.262 \\
\hline One or no TT & $43(11.6)$ & 5 & 21 & & \\
\hline \multicolumn{2}{|l|}{ ntraceptive use } & $(19.2)$ & (80.8) & 1.00 & \\
\hline Ever used & $208(55.9)$ & 13 & 219 & $2.42(1.26,4.64)$ & 0.084 \\
\hline Never used & $164(44.1)$ & $(5.6)$ & $(94.4)$ & & \\
\hline \multicolumn{2}{|l|}{ ıce of delivery } & 5 & 35 & 1.00 & \\
\hline Health facility & $305(82.0)$ & $(12.5)$ & (87.5) & $1.48(0.68,3.24)$ & 0.522 \\
\hline Home & $67(18.0)$ & & 69 & & \\
\hline \multicolumn{2}{|l|}{ lostrum feeding } & $(6.8)$ & $(93.2)$ & 1.00 & \\
\hline Yes & $320(86.0)$ & & & $21.45(10.64,43.22)$ & 0.000 \\
\hline No & $52(14.0)$ & 23 & 306 & & \\
\hline \multicolumn{2}{|l|}{ ther's age } & $(7.0)$ & $(93.0)$ & 1.00 & \\
\hline$>=25$ & $185(49.7)$ & & 38 & $0.33(0.13,0.88)$ & 0.146 \\
\hline$<=24$ & $187(50.3)$ & (11.6) & $(88.4)$ & & \\
\hline \multicolumn{2}{|l|}{$\mathrm{x}$ of the child } & & & 1.00 & \\
\hline Female & $177(47.6)$ & 12 & 196 & $0.80(0.42,1.52)$ & 0.655 \\
\hline Male & $195(52.4)$ & $(5.8)$ & $(94.2)$ & & \\
\hline \multicolumn{2}{|l|}{ mber of births } & 16 & 148 & 1.00 & \\
\hline$<=2$ & $166(44.6)$ & $(9.8)$ & $(90.2)$ & $10.60(1.67,67.444)$ & 0.102 \\
\hline$>4$ & $87(23.4)$ & & & $1.596(0.57,4.47)$ & 0.560 \\
\hline $3-4$ & $119(32.0)$ & 22 & 283 & & \\
\hline \multicolumn{2}{|l|}{ əvious death of a child } & $(7.2)$ & $(92.8)$ & 1.00 & \\
\hline Yes & $59(15.9)$ & & 61 & $1.65(0.64,4.27)$ & 0.498 \\
\hline No & $313(84.1)$ & $(9.0)$ & $(91.0)$ & & \\
\hline \multicolumn{4}{|l|}{ th order } & 1.00 & \\
\hline First & $83(22.3)$ & 11 & 309 & $0.55(0.09,3.24)$ & \\
\hline$>=$ Fourth & $133(35.8)$ & (3.4) & (96.6) & $0.90(0.33,2.43)$ & 666 \\
\hline Second or third & $156(41.9)$ & 17 & 35 & & 0.888 \\
\hline \multicolumn{2}{|l|}{$\begin{array}{l}\text { fe sanitation facilities } \\
\text { Yes }\end{array}$} & (32.7) & $(67.3)$ & 1.00 & \\
\hline Yes & $95(25.5)$ & & & $0.48(0.22,1.03)$ & \\
\hline $\begin{array}{c}\text { No } \\
\text { lid fuel use }\end{array}$ & $277(74.5)$ & $\begin{array}{r}16 \\
(8.6)\end{array}$ & $\begin{array}{r}169 \\
(91.4)\end{array}$ & 1.00 & 0.220 \\
\hline & & & & & \\
\hline
\end{tabular}




\begin{tabular}{|c|c|c|c|}
\hline $\begin{array}{r}12 \\
(6.4)\end{array}$ & $\begin{array}{r}175 \\
(93.6)\end{array}$ & $1.86(0.53,6.51)$ & 0.528 \\
\hline $\begin{array}{r}12 \\
(6.8) \\
16 \\
(8.2)\end{array}$ & $\begin{array}{r}165 \\
(93.2) \\
179 \\
(91.8)\end{array}$ & & \\
\hline $\begin{array}{r}13 \\
(7.8) \\
8 \\
(9.2) \\
7 \\
(5.9)\end{array}$ & $\begin{array}{r}153 \\
(92.2) \\
79 \\
(90.8) \\
112 \\
(94.1)\end{array}$ & & \\
\hline $\begin{array}{r}6 \\
(10.2) \\
22 \\
(7.0)\end{array}$ & $\begin{array}{r}53 \\
(89.8) \\
291 \\
(93.0)\end{array}$ & & \\
\hline $\begin{array}{r}8 \\
(9.6) \\
10 \\
(7.5) \\
10 \\
(6.4)\end{array}$ & $\begin{array}{r}75 \\
(90.4) \\
123 \\
(92.5) \\
146 \\
(93.6)\end{array}$ & & \\
\hline $\begin{array}{r}8 \\
(8.4) \\
20 \\
(7.2)\end{array}$ & $\begin{array}{r}87 \\
(91.6) \\
257 \\
(92.8)\end{array}$ & & \\
\hline $\begin{array}{r}26 \\
(7.3) \\
2 \\
(12.5)\end{array}$ & $\begin{array}{r}330 \\
(92.7) \\
14 \\
(87.5) \\
\end{array}$ & & \\
\hline
\end{tabular}

$\mathrm{COR}=$ crude odds ratio; $\mathrm{Cl}=$ confidence interval; $\mathrm{TT}$ = tetanus toxoid

In multivariate analysis, household size, and colostrum feeding status were significant factors associated with under-five mortality of children (Table 4). Children born in households with less than 6 members had 7.98 times higher odds of dying than those born in households with at least 6 members (AOR $=7.98$, $95 \% \mathrm{Cl}=1.59-40.17, \mathrm{P}<0.05)$. Those children who did not feed colostrum were associated with 17.45 times increased risk of under-five deaths compared to colostrum fed ones $(A O R=17.45,95 \% \mathrm{Cl}=6.54$ $46.55, \mathrm{P}<0.001)$. The wide confidence intervals might be attributable to the small sample size of the study.

Table 4. The factors associated with under-five mortality of children in Haramaya town, east Ethiopia, $2016-2020(n=372$ and $p<0.05)$ 


\begin{tabular}{|c|c|c|c|c|c|}
\hline \multirow[t]{2}{*}{ Tariables } & \multirow[t]{2}{*}{ N (\%) } & \multicolumn{2}{|c|}{$\begin{array}{c}\text { Under-five } \\
\text { mortality }\end{array}$} & \multirow[t]{2}{*}{ AOR (95\% CI) } & \multirow[t]{2}{*}{$\begin{array}{c}\mathrm{P}- \\
\text { value }\end{array}$} \\
\hline & & $\begin{array}{l}\text { Yes } \\
(\%) \\
\end{array}$ & No (\%) & & \\
\hline \multicolumn{6}{|l|}{ icome (ETB) } \\
\hline$>=1700$ & 338 (90.9) & $21(6.2)$ & 317 & 1.00 & \\
\hline$<1700$ & $34(9.1)$ & $7(20.6)$ & $(93.8)$ & $2.40(0.73,7.93)$ & 0.149 \\
\hline \multicolumn{6}{|l|}{ ousehold size } \\
\hline$>5$ & $133(35.8)$ & $6(4.5)$ & & 1.00 & \\
\hline$<=5$ & $239(64.2)$ & $22(9.2)$ & 127 & $7.98(1.59,40.17)$ & 0.012 \\
\hline \multicolumn{6}{|l|}{ ccupation of mother } \\
\hline Daily laborer & & $5(19.2)$ & 217 & 1.00 & \\
\hline House wife & $26(7.0)$ & $13(5.6)$ & $(90.8)$ & $0.25(0.06,1.02)$ & 0.053 \\
\hline Government & $232(62.4)$ & $5(12.5)$ & & $0.54(0.11,2.74)$ & 0.458 \\
\hline employee & $40(10.8)$ & $5(6.8)$ & $21(80.8)$ & $0.53(0.10,2.89)$ & 0.466 \\
\hline Others & $74(8.6)$ & & 219 & & \\
\hline \multicolumn{6}{|l|}{ ontraceptive use } \\
\hline Ever used & $208(55.9)$ & $16(9.8)$ & $35(87.5)$ & $2.33(0.90,6.05)$ & 0.083 \\
\hline Never used & $164(44.1)$ & & $69(93.2)$ & & \\
\hline \multicolumn{6}{|l|}{ olostrum feeding } \\
\hline Yes & $320(86.0)$ & 17 & 196 & $17.45(6.54,46.55)$ & 0.000 \\
\hline No & $52(14.0)$ & $(32.7)$ & $(94.2)$ & & \\
\hline \multicolumn{6}{|l|}{ lother's age } \\
\hline$>=25$ & 185 (49.7) & $16(8.6)$ & $(90.2)$ & $0.38(0.10,1.41)$ & 0.147 \\
\hline$<=24$ & $187(50.3)$ & $12(6.4)$ & & & \\
\hline \multicolumn{6}{|l|}{ umber of births } \\
\hline$<=2$ & $166(44.6)$ & $13(7.8)$ & (96.6) & $5.01(0.75,33.42)$ & 0.096 \\
\hline$>4$ & $87(23.4)$ & $8(9.2)$ & $35(67.3)$ & $1.31(0.35,4.88)$ & 0.686 \\
\hline \multirow[t]{9}{*}{$3-4$} & $119(32.0)$ & 7 (5.9) & & & \\
\hline & & & 169 & & \\
\hline & & & $\begin{array}{r}(91.4) \\
175\end{array}$ & & \\
\hline & & & $(93.6)$ & & \\
\hline & & & 153 & & \\
\hline & & & (92.2) & & \\
\hline & & & 79 (90.8) & & \\
\hline & & & 112 & & \\
\hline & & & $(94.1)$ & & \\
\hline
\end{tabular}

$\mathrm{AOR}=$ adjusted odds ratio; $\mathrm{Cl}=$ confidence interval

\section{Discussion}

The prevalence rate of under-five mortality in this study was 75 per 1000 live births which is higher than 37 under-five deaths per 1000 live births report from Bhutan National Health Survey 2012 (Dendup et al., 2018) to 67 per 1000 live births in Ethiopia from EDHS 2016 data analysis (Berhanu, 2019). However, it is lower than 87.7 mortalities per 1000 live births evidence from the Nepal Demographic and Health Survey (2001-2016) (Ghimire et al., 2019). The explanation for this difference might be due to differences in sample size, study setting, and operational definition. 
In this study, household size was significantly associated with under-five mortality. This study found that household size was inversely associated with under-five mortality consistent with the finding from Bhutan (Dendup et al., 2018). The findings support the view that larger households may have better resources such as more experienced child care providers and more working-age adults contributing to the household income. In contrast, another finding in the Ethiopian Somali Regional State suggested that the mortality risk of childen increases as the size of the family increases (Solomon et al., 2017). To this view, larger family size may indicate more children, leading to intra-sibling competition for limited resources and inadequate attention and care to children heightening their mortality risk. However, the finding in this study suggests that larger family size is protective against UFM in Haramaya town, possibly through more people to care for the child and resources.

The other prominent factor associated with under-five mortality in this study was colostrum feeding practice after birth. The death rate was significantly higher among children not colostrumfed in line with the study finding from Bhutan (Dendup et al., 2018). Colostrum is the first milk containing proteins, vitamin A and maternal antibodies. A study conducted in the Afambo district of Afar Regional State showed that colostrum feeding was significantly associated with stunting, wasting and underweight (Misgan et al., 2016). The rest of the variables were not significantly associated with UFM in this study. For instance, there was no association between UFM and mother's age unlike the study result in other parts of Ethiopia which stated that it was significantly lower among children born from mothers whose age less than or equal to 24 compared to those born from the reference group (Berhanu, 2019). Mother's education was also not associated with UFM in Haramaya town. A similar report was obtained in a study from Ethiopian Somali Regional State (Solomon et al., 2017) and other parts of Ethiopia (Chaltu et al., 2019). The findings of this study suggest that strengthening health education particularly on exclusive breast feeding practice can improve child survival.

\section{Strengths and Limitations of the Study}

This study is a first of its kind to be undertaken in Haramaya town on under-five mortality. Its high response rate, more than $95 \%$, makes it generalizable to the target population. The use of valid survey methods lends to the study's credibility. Additionally, the use of an appropriate theoretical framework relevant to developing countries to assess under-five mortality also makes this study strong. The most recent singleton live births five years before the survey were considered for analyses to reduce maternal recall bias.

However, this study also had the following limitations. Firstly, the cross-sectional design of the study prevents drawing causal inferences on the associations revealed. The study design might have introduced recall bias and social desirability biases because of the nature of self-reported data in this study. The sample size used is small relative to that of previous studies. The survey only interviewed mothers who are alive, which could have led to the underestimation of U5MR and the effect of various factors. Another drawback is that this research was unable to access the age interval where most deaths 
occurred and it also could not determine the causes of death. Besides, as the study was conducted in a single town, the results might not be representative of the country.

\section{Conclusions}

The study suggests that 75 per 1000 live births die before celebrating their fifth birth day in Haramaya town. Household size and colostrum feeding status are the factors associated with under-five mortality of children in the town.

\section{Recommendations}

Based on the finding of this study, the Haramaya town health office should disseminate information to the mothers about the benefits of feeding their children colostrum and promote the practice. The office, in collaboration with other relevant sectors and programs, should do its best in strengthening child care services.

East Hararghe zonal health department should take part in the allocation of sufficient budget for all these activities including research. It should also closely monitor and evaluate changes that will be there.

In addition, further research at the regional, as well as national level, will enable us to understand the magnitude and associated factors of children's mortality under-five using a larger sample size and including variables not included in this study like mother's age at first birth.

\section{Declarations}

\section{BIOGRAPHICAL SKETCH}

I, Mohammed Ahmed, was born on $5^{\text {th }}$ January 1990, in a small village known as Oda Bishani in Bedeno district of East Hararghe zone, Oromia. I was grown and completed elementary school there, and then went to Bedeno secondary school. I joined Jimma University on $6^{\text {th }}$ November 2008, and graduated on $20^{\text {th }}$ October 2012, as Health Officer. I have been serving the public since $10^{\text {th }}$ November 2012 , with the same profession.

\section{ACKNOWLEDGEMENTS}

Before all, I would like to thank the almighty ALLAH for giving me the courage and vigor in the whole process of the study

I also would like to give my deepest gratitude to my primary advisor Mr. Melake Demena and Mr. Zelalem T/Mariam for their continuous support and valuable advice

Next, my deeper appreciation and great thanks go to Mr. Behailu Hawulte, the department coordinator who has been directing me all along 
I am also grateful to Haramaya University SRP (Student Research Program) for allowing me to do my research

Last but not least, my deep thanks to librarians for their cooperation during the search for documents

\section{Abbreviations}

CM: Child Mortality

EDHS: Ethiopian Demographic Health Survey

ETB: Ethiopian Birr

HDI: Human Development Index

HDSS: Health and Demographic Surveillance System

IHRERC: Institutional Health Research Ethics Review Committee

IM: Infant Mortality

MDG: Millennium Development Goal

ORS: Oral Rehydration Solution

SDG: Sustainable Development Goal

U5MR: Under-five Mortality Rate

UFM: Under-five Mortality

\section{References}

Adedokun, O., O. Adeyemi, C. Dauda. 2017. Child marriage and maternal health risks among young mothers in Gombi, Adamawa State, Nigeria: implications for mortality, entitlements and freedoms. Afr Health Sci 16(4): 986-999.

Alimohamadi, Y., F. Khodamoradi, M. Khoramdad, M. Shahbaz, F. Esmaeilzadeh. 2019. Human development index, maternal mortality rate and under 5 years mortality rate in West and South Asian countries, 1980-2010: an ecological study. East Mediterr Health J 25(3): 189-196.

Amare, D., J. Ojal, B. Karia, E. Bauni, M. Oreinde. 2016. Under-five mortality rate variation between the Health and Demographic Surveillance System (HDSS) and Demographic and Health Survey (DHS) approaches. BMC Public Health 16(1): 1118. 
Amoako Johnson, F., M. Abu, C. E. Ustazi. 2019. Geospatial correlates of early marriage and union formation in Ghana. PLoS One 14(10): e0223296.

Anafcheh, T., M. Yaghoubi Doust, M. Mojadam, R. Mirkazemi, M. A. Khafaie. 2018. Temporal and spatial distribution of under-five mortality and factors associated with multiple cases of under-five deaths within a family in the rural area of Khuzestan, Southern Iran. Sci Rep 8(1): 17930.

Berhanu Teshome Woldeamanuel. 2019. Socioeconomic, Demographic, and Environmental Determinants of Under-5 Mortality in Ethiopia: Evidence from Ethiopian Demographic and Health Survey, 2016. Child Development Research 2019: 15.

Biniyam, S., A. Fessahaye, B. Tefera. (2018). Sanitation practice and associated factors among slum dwellers residing in urban slums of Addis Ababa, Ethiopia: A community based cross-sectional study. Journal of Public Health and Epidemiology_10 (10): 370-377.

Cao, H., J. Wang, Y. Li, D. Li, J. Guo, Y. Hu, et al. 2017. Trend analysis of mortality rates and causes of death in children under 5 years old in Beijing, China from 1992 to 2015 and forecast of mortality into the future: an entire population-based epidemiological study. BMJ Open 7(9): e015941.

Central Statistical Agency (CSA) [Ethiopia]. 2016. Ethiopia Demographic and Health Survey 2016. Addis Ababa, Ethiopia, and Rockville, Maryland, USA: CSA and ICF.

Chaltu, F., G. Masrie, S. Tamrat. 2019. Proximate Determinants of Under-Five Mortality in Ethiopia: Using 2016 Nationwide Survey Data. Pediatric Health, Medicine and Therapeutics 2019(10): 169-176.

Choudhary, T. S., B. Sinha, A. Khera, N. Bhandari, Y. Chu, B. Jackson, et al. 2019. Factors associated with the decline in under-five diarrhea mortality in India: a LiST analysis. J Glob Health 9(2): 020804.

Chowdhury, A. H., S. M. A. Hanifi, M. N. Mia, A. Bhuiya. 2017. Socioeconomic inequalities in under-five mortality in rural Bangladesh: evidence from seven national surveys spreading over 20 years. Int J Equity. Health 16(1): 197.

Dendup, T., Y. Zhao, D. Dema. 2018. Factors associated with under-five mortality in Bhutan: an analysis of the Bhutan National Health Survey 2012. BMC Public Health 18(1): 1375.

Dereje, T. Z., M. F. Haile, W. L. Demeke, P. K. Swain. 2018. Determinants of Under-Five Mortality in Ethiopia: an Application of Cox Proportional Hazard and Frailty Models. Turkiye Klinikleri J Biostat 10(2): 123-36.

Ethiopian Public Health Institute (EPHI) [Ethiopia] and ICF. 2019. Ethiopia Mini Demographic and Health Survey 2019: Key Indicators. Rockville, Maryland, USA: EPHI and ICF.

Gebretsadkan, G. G., T. Helen, B. Kidanemaryam, M. Afework, M. Hajira, G. Abebe, et al. 2020. Early initiation of breastfeeding, colostrum avoidance, and their associated factors among mothers with under 
one year old children in rural pastoralist communities of Afar, Northeast Ethiopia: a cross-sectional study. BMC Pregnancy and Childbirth 2020(20): 448.

Ghimire, P. R., K. E. Agho, O. K. Ezeh, A. M. N.Renzaho, M. Dibley, C. Raynes-Greenow, et al. 2019. UnderFive Mortality and Associated Factors: Evidence from the Nepal Demographic and Health Survey (20012016). Int J Environ Res Public Health 16(7): 14.

Glynn, J. R., B. S. Sunny, B. Destavola, A. Dube, M. Chihana, A. J. Price, et al. 2018. Early school failure predicts teenage pregnancy and marriage: A large population-based cohort study in northern Malawi. PLoS One 13(5): e0196041.

Haile Arefayne Shishaye and Ararso Nagari. 2016. Hydrogeochemical Analysis and Evaluation of the Groundwater in the Haramaya Well Field, Eastern Hararghe Zone, Ethiopia. J Hydrogeol Hydrol Eng 5(4): 10.

Johnface F. Mdala and Robert Mash. 2015. Causes of mortality and associated modifiable health care factors for children (< 5-years) admitted at Onandjokwe Hospital, Namibia. Afr J Prim Health Care Fam Med 7(1): 8.

Kamal, S. M. Mostafa and Che Hashim Hassan. 2015. Child Marriage and Its Association With Adverse Reproductive Outcomes for Women in Bangladesh. Asia-Pacific Journal of Public Health 27(2): 14921506.

Kazutaka Sekine and Daniel J. Carter. 2019. The effect of child marriage on the utilization of maternal health care in Nepal: A cross-sectional analysis of Demographic and Health Survey 2016. PLoS One 14(9): e0222643.

Kipp, A. M., M. Blevins, C. A. Haley, K. Mwinga, P. Habimana, B. E. Shepherd, et al. 2016. Factors associated with declining under-five mortality rates from 2000 to 2013: an ecological analysis of 46 African countries. BMJ Open 6(1): e007675.

Luseno, W. K., L. Zhang, B. J. Iritani, S. Hartman, S. Rusakaniko, D. D. Hallfors, et al. 2016. Influence of school support on early marriage experiences and health services utilization among young orphaned women in Zimbabwe. Health Care Women Int 38(3): 283-299.

Melkamu, D., O. Lemessa, A. Nega. 2015. Small area clustering of under-five children's mortality and associated factors using geo-additive Bayesian discrete-time survival model in Kersa HDSS, Ethiopia. Spatial and Spatio-temporal Epidemiology 2016(16): 43-49.

Minale Bezie and Dagne Addisu. 2019. Determinants of early marriage among married women in Injibara town, north West Ethiopia: community-based cross-sectional study. BMC Womens Health 19(1): 134.

Misgan, L. L., A. Taye, H. Yohannes. 2016. The Role of Colostrum Feeding on the Nutritional Status of Preschool Children in Afambo District, Northeast Ethiopia: Descriptive Cross Sectional Study. European 
Journal of Clinical and Biomedical Sciences 2( 6): 87-91.

Nega, A., O. Lemessa, B. Negga, D. Melake, Z. Desalew, A. Wondimye, et al. (2015). "HDSS Profile: The Kersa Health and Demographic Surveillance System." International Journal of Epidemiology,_2016 45(1): 94-101.

Rostami, M., A. Jalilian, B. Hamzeh, Z. Laghaei. 2015. Modeling and forecasting of the under-five mortality rate in Kermanshah province in Iran: a time series analysis. Epidemiol Health 37: e2015003.

Sandoy, I. F., M. Mudenda, J. Zulu, E. Munsaka, A. Blystad, M. C. Makasa, et al. 2016. Effectiveness of a girls' empowerment programme on early childbearing, marriage and school dropout among adolescent girls in rural Zambia: study protocol for a cluster randomized trial. Trials 17(1): 588.

Shewayiref, G. G. and M. F. Setegn. 2020. Under-Five Mortality and Associated Risk Factors in Rural Settings of Ethiopia: Evidences from 2016 Ethiopian Demographic and Health Survey. Advances in Public Health 2020: 13.

Solomon, G. B., G. H. Fekade, D. N. Tewodros. 2017. Under-Five Mortality of Children and its Determinants in Ethiopian Somali Regional State, Eastern Ethiopia. Health Sci J 11(3): 507.

United Nations. 2018. The 2030 Agenda and the Sustainable Development Goals: An opportunity for Latin America and the Caribbean (느/G.2681-P/Rev.3), Santiagoㅇ_2018.

Winfred A. Avogo and Oluwaseyi D. Somefun. 2019. Early Marriage, Cohabitation, and Childbearing in West Africa. J Environ Public Health 2019: 9731756.

Yaya, S., G. Bishwajit, F. Okonofua, O. A. Uthman. 2018. Under five mortality patterns and associated maternal risk factors in sub-Saharan Africa: A multi-country analysis. PLoS One 13(10): e0205977.

Yaya, S., M. Ekholuenetale, G. Tudeme, S. Vaibhav, G. Bishwajit, B. Kadio, et al. 2017. Prevalence and determinants of childhood mortality in Nigeria. BMC Public Health (2017) (17): 485.

Yohannes, M. A., A. F. Senafikish, B. M. Zelalem, B. W. Shimelash. 2017. Childhood Mortality: Trends and Determinants in Ethiopia from 1990 to 2015-A Systematic Review. Advances in Public Health 2017: 10.

\section{Figures}




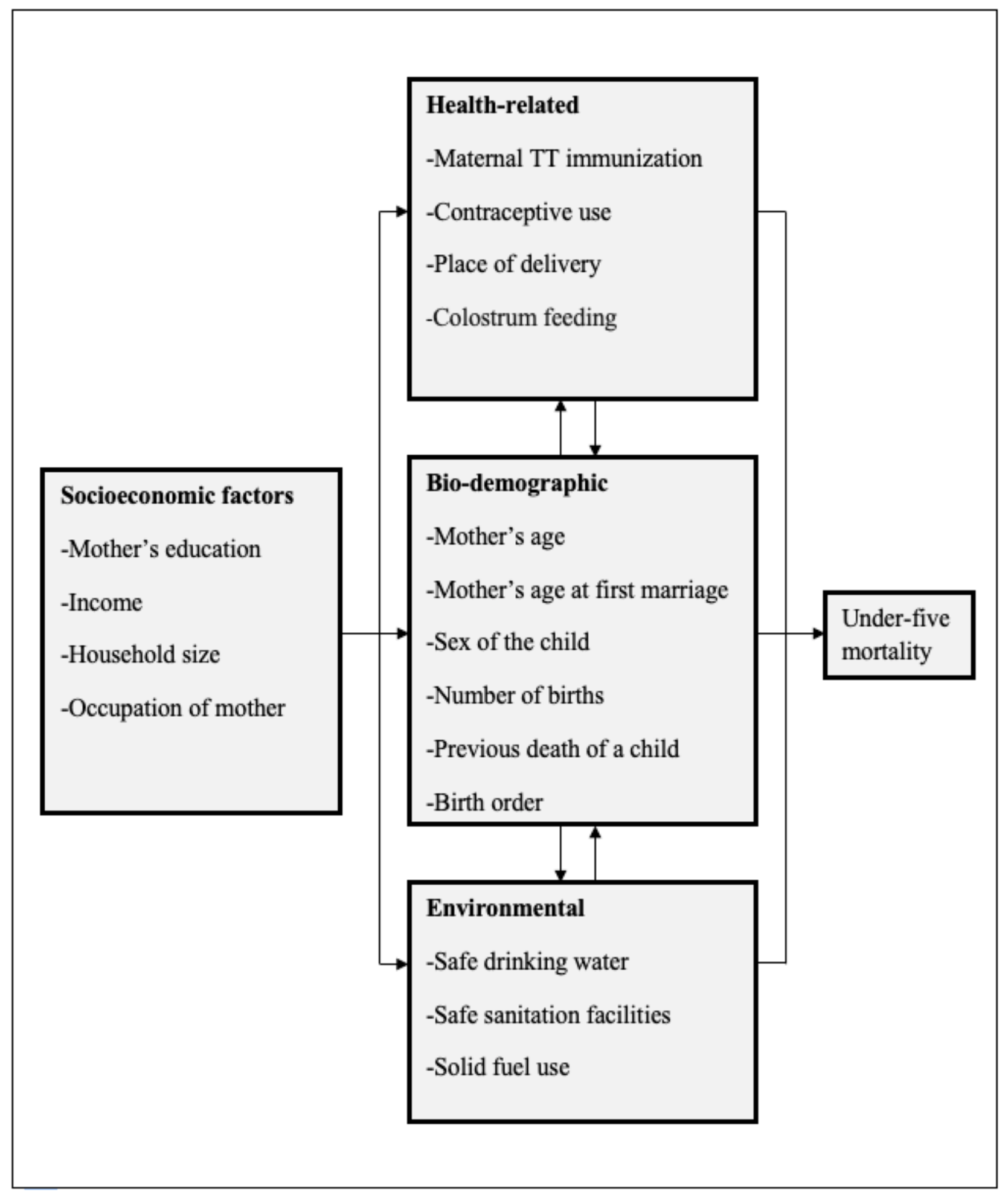

Figure 1

Conceptual framework illustrating factors influencing under-five mortality of children adapted and modified from different literatures reviewed 


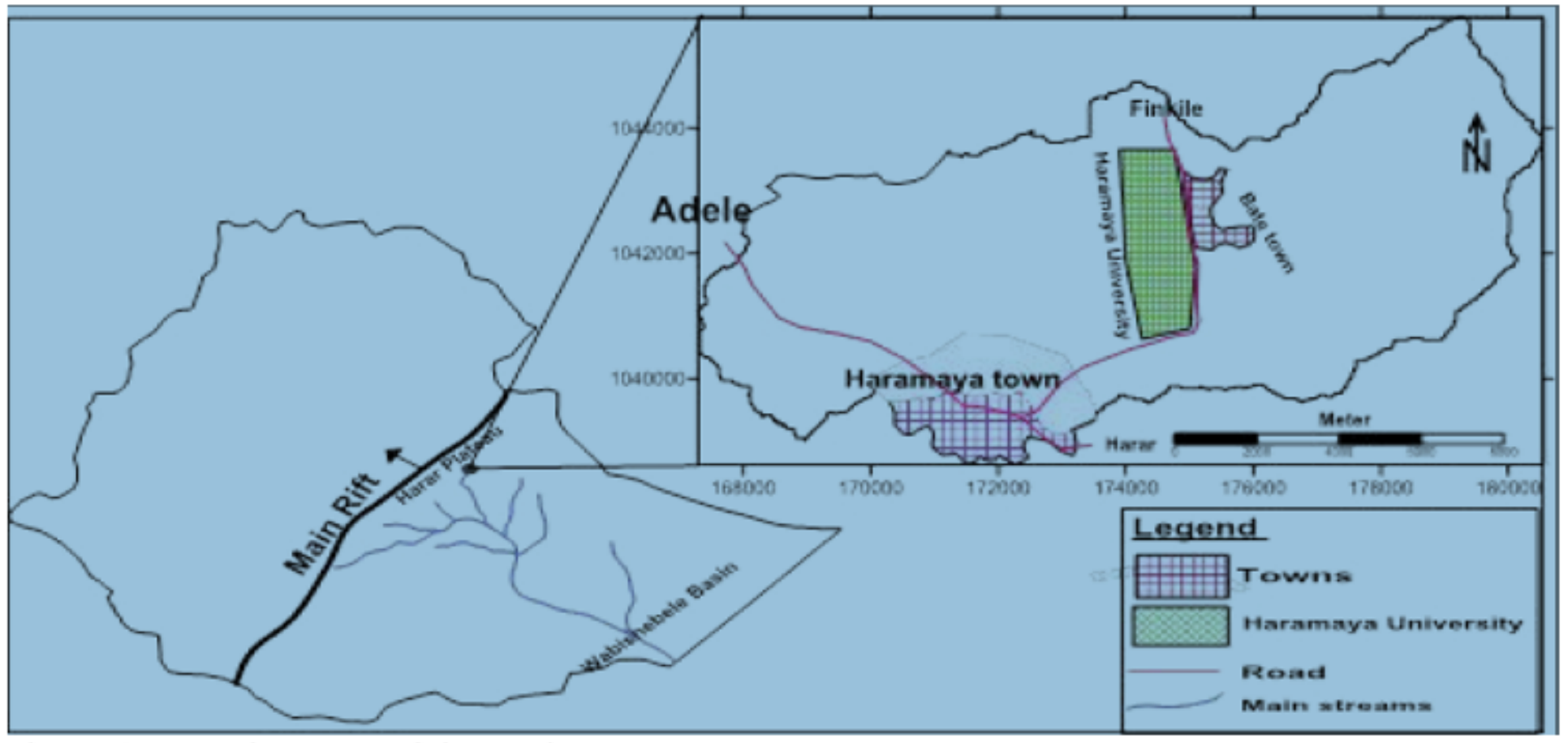

Figure 2

Location map of the study area 


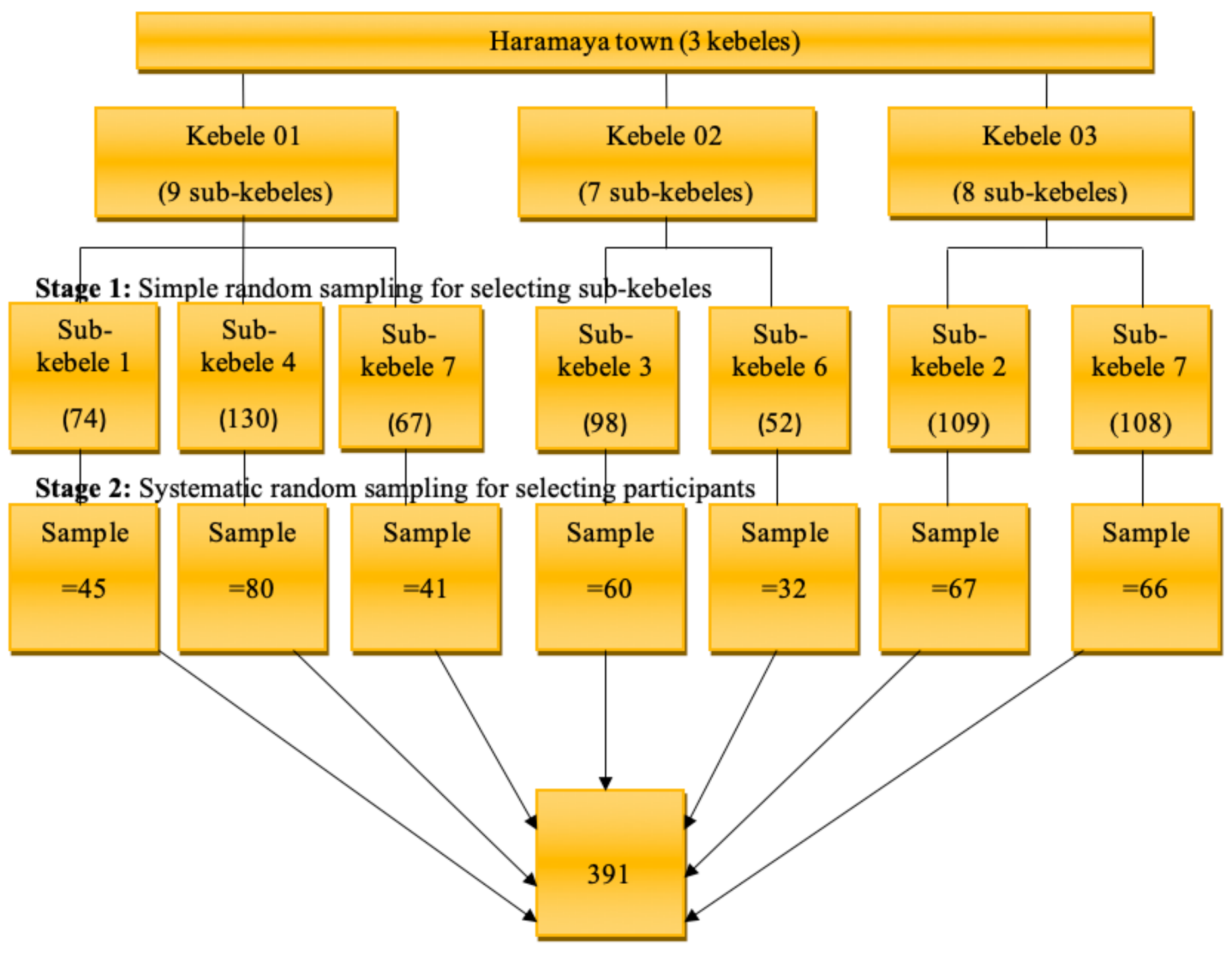

Figure 3

Sampling procedure of selecting sub-kebeles and study participants in Haramaya town

\section{Supplementary Files}

This is a list of supplementary files associated with this preprint. Click to download.

- ANNEXES.docx 